\title{
Harvey Cushing and Philip Hench: Pituitary Basophilism Meets Cortisone Excess
}

\author{
Claudio E. Kater \\ LUCIO VILAR \\ JOHN NEWELL-PRICE
}

Disciplina de Endocrinologia, Departamento de Medicina, Universidade Federal de São Paulo, UNIFESP/EPM (CEK), São Paulo, SP; Hospital das Clínicas,

Divisão de Endocrinologia, Universidade Federal de Pernambuco (LV), Recife, PE \& Academic Unit of Diabetes, Endocrinology \& Metabolism, School of Medicine and Biomedical Science, The University of Sheffield (JN-P), Sheffield, UK.

\section{Celebration of the 75th Anniversary of Cushing's Syndrome}

T IS OPPORTUNE THAT THIS ESPECIAL issue of the Brazilian Journal of Endocrinology and Metabolism comes out just in time to celebrate the $75^{\text {th }}$ anniversary of the original description of the disease that turned out to be known as Cushing's syndrome.

Harvey Williams Cushing (April 8, 1869 - October 7, 1939) was a renowned neurosurgeon at the inception of endocrinology, and is distinguished today as the "father of modern neurosurgery".

A graduate of Yale College, Cushing spent most of his academic and professional life at Johns Hopkins and at Harvard Medical Schools, where his innovative and skilful approach to neurosurgery, introducing rigid homeostasis, asepsis, electrocoagulation, and other technical procedures, reduced mortality rates from brain surgery from 50 to $10 \%$ (1).

Cushing was puzzled by a 23 -year-old patient that had central obesity with contrasting skinny arms and legs, presence of bruises and large purplish striae spread upon a very thin, fragile, and almost translucent skin, a round and plethoric face resembling a "full moon", prominent accumulation of dorsal fat, described as "buffalo hump", in addition to hirsutism, amenorrhea, hypertension, and hyperglycemia.

Although the hypothalamic-pituitary-adrenal axis and its interconnections were barely known at that time, Cushing described this astonishing condition as "pituitary basophilism". Little was known about adrenal biosynthesis and corticosteroid production by the "supra renal capsules".

Cortisol excess, either by primary adrenal production or secondary to ACTH excess, and its resulting clinical manifestations are the quintessence of Cushing's syndrome as we know it today. By 1912, however, little did Cushing know about these mechanisms when he published his initial monograph: "The pituitary body and its disorders" (2), in which he described the case of Minnie G., his first patient with typical stigmata of hypercortisolism.

However, it was not until 20 years later that Cushing gathered another eleven patients with similar clinical characteristics who were reported in 1932 in a yet another seminal work: "Pituitary basophilism" (3).

The florid clinical manifestations were ascertained to some sort of pituitary abnormality called "basophilism", even though only three of the 12 reported patients were identified with a pituitary tumor. Indeed, in his landmark report, Cushing unintentionally described what appears to be the first cases of a "polyglandular syndrome", since at autopsy several cases also presented hyperplasia of the adrenal glands in association with pituitary adenomas (3).

Most interestingly, another patient from his series, with identical manifestations, had an adrenal adenoma found at autopsy, but no physiological relationship had been established. Only a few years later adrenal tumors were shown to cause the syndrome in some cases (4). 
Mayo Clinic, in Rochester, Minnesota, was the center of several medical events in the late 40s. By 1936, just three years before Harvey Cushing's death at the age of 70, Edward Carl Kendall with his group of chemists was developing a series of studies aiming at the isolation of crystalline preparations of the adrenal cortex with biological activity. The structure of several adrenal steroids was rapidly elucidated and Kendal and co-workers were designating them in alphabetical order as they were isolated; compounds A through $\mathrm{F}$ have been prepared and compound $\mathrm{E}$ was later identified as cortisone.

At the same time, Tadeus Reichstein and his group in Zurich, Switzerland, were conducting similar studies, but labeling their isolated products with a different terminology, whereas Wintersteiner and Pfiffner, also in the USA, were giving them yet different names (for example, Kendall's compound E was Reichstein's compound Fa, and Pfiffner's compound F), starting a confusing nomenclature that took years to be clarified.

Finally, the first synthetic adrenocortical steroid was produced by Reichstein's group in 1937: 11-deoxycorticosterone (DOC). Whereas other 11-deoxy compounds were produced soon thereafter, it took another six years for Reichstein to synthesize the first 11-oxygenated steroid, 11-dehydrocorticosterone or compound $\mathrm{A}$, which was disappointingly devoid of biological activity in the treatment of Addison's disease.

However, in 1946, Lewis Sarett working with Merck laboratories, produced a partial synthesis of the biologically active product, compound E, and by 1948 this compound, now designated cortisone, was being synthesized in gram quantities and showing encouraging effects in the control of Addisonian patients.

Another interesting fact took place at Mayo Clinic. Philip Showalter Hench (February 2, 1896 - March $30,1965)$ - the first rheumatologist and head of the Rheumatology Service at Mayo Clinic -, and his group observed in patients with rheumatoid arthritis (at that time thought to be caused by some sort of infectious disease) the beneficial clinical effects of jaundice and pregnancy. He also observed significant amelioration in the post-operative period following some surgeries.

During the Second World War years, Kendall in collaboration with Sarett of Merck, managed to produce large amounts of compound E. A strategic research plan for the industrial development of synthetic adrenal corticosteroids had been boosted by the US Government at that critical period, based on the false premise that Luftwaffe pilots were able to fly at higher altitudes (above 40.000 feet) because they were being injected with steroid hormones, and also by information obtained from the US Intelligence that German submarines were transporting huge amounts of cattle adrenals bought from Argentina. A conference of endocrinologists, called upon by Merck, discussed the possible clinical uses of the hormone. Hench, not initially among the grantees, finally managed to obtain a 5 -g supply from James Carlisle and Randolph Major at Merck, thanks to his friendship with Kendall.

By 1948, they started injecting cortisone preparations in patients with rheumatoid arthritis and documenting the splendid beneficial effects on muscle stiffness and soreness. The first injection of $50 \mathrm{mg}$ was administered to a 29-year-old Mrs. Gardner by Hench's colleague, Charles Slocumb, on September 21. At that time, the 100-mg per day dose seemed too large, but both Hench and Kendall were anxious to not inadvertently underdose. During the next several months another 12 selected patients received cortisone injections and experienced dramatic clinical improvements. Scientific communication was published (5) and immediately circulated in the lay press. In 1950, Hench, Kendall, and Reichstein were bestowed with and shared the Nobel Prize in Medicine or Physiology for their contribution.

Although Thomas Addison is recognized to inaugurate the modern era of clinical adrenal physiology almost 100 years earlier, when he presented his classic treatise "On Disease of the Supra Renal Capsules" in 1855 (6), the physiological chemistry of adrenocortical hormones was still largely unknown, as stated by Robin Fåhraeus, member of the Swedish Royal Academy of Sciences, when addressing the 1950 Nobel Prize laureates: "Doctor Philip Hench, Professor Edward Kendall, and Professor Tadeus Reichstein. Together your researches have contributed to the enlightenment of the extremely complicated physiological chemistry of the suprarenal glands, which since their discovery for a long time have been assumed to play no other part than to fill up the vacuum between the kidneys and the diaphragm. Your contributions have already fulfilled the hopes of therapeutic success in a field hitherto almost inaccessible".

Several subsequent studies were conducted around the world confirming the beneficial clinical effects of cortisone administration in a host of other inflammatory diseases. Unfortunately, it did not take too long to observe that such high therapeutic doses of cortisone also produce a range of significant adverse effects that were immediately recognized to resemble those associated with the clinical manifestations described in Cushing's pituitary basophilism paper. 
Thus, cortisone excess or hyperadrenocortisonism and Cushing's syndrome became synonymous.

Nevertheless, these important historical events in medicine prompted the recognition of Cushing's syndrome as a disorder resulting from glucocorticoid excess, and a better understanding of the mechanisms and interplay of the hypothalamic-pituitary-adrenocortical axis, as well as the physiologic and pathophysiologic affects of natural and synthetic corticosteroids in the human body, opened a vast new road for investigation in endocrinology.

This up-to-date especial issue of Endocrinology and Metabolism (Arquivos Brasileiros de Endocrinologia \& Metabologia) is the first in the series dedicated to one selected disorder: Cushing's syndrome. As guest editors, we were fortunate to be able to count with the authoritative cooperation of enthusiastic colleagues from centers in the UK, USA, Italy, Canada, Greece, and Brazil. We are indebted to each and every one of them for sharing with us important new ideas and concepts on this ever-growing medical complex that is "Cushing's syndrome".

\section{REFERENCES}

1. Bliss M. Harvey Cushing: A Life in Surgery. New York: Oxford University Press, 2005.

2. Cushing $\mathrm{H}$. The pituitary body and its disorders: Clinical states produced by disorders of the hypophysis cerebri. Philadelphia: J.B. Lippincott, 1912 (monograph).
3. Cushing $\mathrm{H}$. The basophil adenomas of the pituitary body and their clinical manifestations (pituitary basophilism). Bull Johns Hopkins Hosp 1932;50:137-95.

4. Walters W, Wilder RM, Kepler EJ. The suprarenal cortical syndrome with presentation of ten cases. Ann Surg 1934;100:670-88.

5. Hench PS, Kendall EC, Slocumb CH, Polley HF. Effects of cortisone acetate and pituitary ACTH on rheumatoid arthritis, rheumatic fever and certain other conditions. Arch Intern Med 1950;85:545-666.

6. Addison T. On the constitutional and local effects of disease of the supra-renal capsules. London: Samuel Righley, 1855.

\section{Other reference sources}

1. Bethune JE. The adrenal cortex (A scope ${ }^{\circledR}$ monograph). Kalamazoo: The Upjohn Company, 1974.

2. Lloyd M. Philip Showalter Hench, 1896-1965 (Heberden Hystorical Series/Series Editor: M Jayson). Rheumatology 2002;41:582-4

3. Stewart PM. The adrenal cortex. In: Larsen PR, Kronenberg HM, Melmed S, Polonsky KS. Williams textbook of endocrinology. $10^{\text {th }}$ edition. Philadelphia: Saunders, 2003. pp. 491-551.

4. Harvey Cushing: A journey through his life. Available at: $<$ http://www.med.yale.edu/library/historical/cushing/index.ht $\mathrm{ml}>$. Accessed in October 2007.

5. The Harvey W. Cushing collection. Available at: $<$ http://www.medicalarchives.jhmi.edu/sgml/cushing.html>. Accessed in October 2007.

Address for correspondence:

Claudio E. Kater

Associate Professor of Medicine

Adrenal and Hypertension Unit

Division of Endocrinology, Department of Medicine

Federal University of São Paulo

Rua Pedro de Toledo 781, 13 th floor

04039-042 São Paulo, SP 